Trab. Ling. Aplic., Campinas, 46(1): 63-78, Jan./Jun. 2007

\title{
LETRAMENTOSDIGITAIS-ALEITURACOMO RÉPLICAATIVA
}

\author{
ROXANEROJO \\ UNICAMP
}

\begin{abstract}
RESUMO
$\mathrm{O}$ artigo inicialmente resume rapidamente algumas das características mais frequientemente apontadas do texto eletrônico e algumas das decorrências dessas características para as práticas de leitura e para os letramentos digitais. A seguir, busca contrastar duas propostas de leitura em esfera didática ou escolar, de divulgação da ciência, uma em ambiente digital e outra em mídia impressa, sobretudo para avaliar o lugar que é designado ao leitor-aluno em cada uma delas e os tipos de atuação lingüístico-discursiva que lhe são solicitados, de maneira a discutir as práticas de letramento (crítico) que se dão nesses contextos.

Palavras-chave: leitura; letramentos críticos; letramentos digitais.
\end{abstract}

\section{ABSTRACT}

In this paper, we initially mention some of the aspects of electronic texts most frequently pointed out by authors, and some of the impacts of these aspects on reading practices and digital literacy. Following, we analyse two reading materials of scientific texts elaborated to teach reading of scientific texts: one on virtual ambience and the other printed. The goal is to evaluate, for each material, the discursive place assigned to the student-reader and the types of discursive acts demanded of him or her, aiming to discuss the (critical) literacy practices that the materials provide.

Key-words: reading; critical literacy; digital literacy.

\section{INTRODUÇÃO}

Embora hoje em dia os textos em ambiente digital estejam, a cada dia mais, multissemióticos, multimidiáticos e hipermediáticos (Lemke, 1998), sua matéria prima é principalmente e desde sempre a linguagem escrita. A Internet tornou possível, como afirma Beaudouin (2002), que passássemos a conversar com as mãos e os olhos, ao invés de com a boca e os ouvidos. O ambiente digital escrituralizou (Lahire, 1993) mesmo a conversa do dia a dia.

Portanto, os atos de ler e escrever são ainda mais fundamentais na interação virtual que em nossas interações cotidianas, no mundo atual. $\mathrm{E}$ isso torna relevante e urgente o estudo e a discussão dos letramentos digitais.

Muitos autores chamam a atenção para os impactos que o ambiente digital tem sobre a autoria e as práticas e protocolos de leitura. Chartier (1997, p. 88-91) vai, por exemplo, dizer que 
ROJO - Letramentos digitais - a leitura como réplica ativa

o novo suporte ${ }^{1}$ do texto permite usos, manuseios e intervenções do leitor infinitamente mais numerosos e mais livres do que qualquer uma das formas antigas do livro. [...] O leitor não é mais constrangido a intervir na margem, no sentido literal ou no sentido figurado. Ele pode intervir no coração, no centro. Que resta então da definição do sagrado, que supunha uma autoridade impondo uma atitude de reverência, de obediência ou de meditação, quando o suporte material confunde a distinção entre o autor e o leitor, entre a autoridade e a apropriação?

Para Beaudouin (2002), o texto eletrônico altera as relações entre leitura e escrita, autor e leitor; altera os protocolos de leitura ${ }^{2}$. Uma de suas particularidades é a de que leitura e escrita se elaboram ao mesmo tempo, numa mesma situação e num mesmo suporte, o que é nitidamente diverso da separação existente entre a produção do livro (autor, copista, editor, gráfico) e seu consumo pelo leitor nas eras do impresso ou do manuscrito. Isso porque, a Internet, por sua estrutura hipertextual ${ }^{3}$ articula espaços de informação a ferramentas de comunicação, propondo um conjunto de dispositivos interativos que dão lugar a novos escritos. Um link para o email ou o site do autor permitem réplicas imediatas ao que está sendo lido; comentários, sugestões, apreciações de leitor ganham, na Internet - nos blogs, por exemplo - visibilidade inédita. Neste sentido é que o leitor não está mais restrito a observações à margem. Chega-se mesmo a escrever romances a muitas mãos com os leitores, como foi, por exemplo, a experiência de Mário Prata ao escrever, em texto eletrônico, Os Anjos de Badaró - que o autor qualifica de novela pós-eletrônica ${ }^{4}$ - em colaboração com os leitores, seus co-autores.

Muitos autores sublinham a suposta liberdade ou submissão do leitor em relação aos links semeados pelo autor nos protocolos de leitura do texto eletrônico. De tudo isso, não

${ }^{1}$ Entendido como objeto material em que o texto se inscreve. Pierre Lévy (1997, 1998, p. 17), por exemplo, discorda de que a tela possa ser vista como um novo tipo de suporte, na medida, por exemplo, em que o texto aí não se inscreve, mas se afixa provisoriamente. O texto eletrônico, para ele, é desterritorializado, habitante ubíquo do ciberespaço, até porque o que se inscreve não é o texto, mas sua digitalização, que se traduz e se afixa em lugares os mais inesperados, a cada acesso.

${ }^{2}$ Podemos definir protocolos de leitura como os diversos procedimentos e traços que os processos de mise-en-texte (redação) do autor e de mise-en-page (diagramação) e mise-en-livre (projeto gráficoeditorial) do editor deixam para o leitor, buscando levá-lo a certas práticas de leitura, a certas maneiras de ler, e, assim, garantir o efeito de sentido intentado. Podemos pensar, por exemplo, na sub-intitulação, na paragrafação, nas notas de rodapé, nos boxes e imagens, na ocupação da página.

${ }^{3}$ Lemke (1998) define hipertexto como aquele que permite que saltemos de um texto a outro e de um ponto de saída a múltiplos portos de ancoragem, por meio da inserção de linkagens permitidas em ambiente digital. Aponta também para a importância dos textos hipermidiáticos nos letramentos contemporâneos, afirmando que a próxima geração de ambientes de aprendizagem interativos inclui imagens visuais, som, vídeo e animação, todos práticos quando velocidade e capacidade de armazenamento permitem acomodar essas formas de significação topológicas densamente informativas. [...] Essas mídias mais topológicas não podem ser indexadas e inter-referenciadas por seu conteúdo (o que a figura mostra, diz) mas precisam ser tratadas como 'objetos' integrais. Mesmo assim, como objetos, elas podem se tornar nódulos para hiperlinks, e assim nasceu a hipermídia (ver Landow \& Delany, 1991; Bolter, neste volume). A importância dos letramentos multimidiáticos correspondentes já foi discutida [...] (retirado de http://academic.brooklyn.cuny.edu/ education/jlemke/reinking.htm, acessado em 12/08/2006, tradução minha).

${ }^{4}$ http://www.marioprataonline.com.br/, acessado em 26/03/2007. 
resta dúvida que a terceira revolução, como chama Chartier a era do texto eletrônico, alterou profundamente as relações entre autor-texto-leitor e levou-nos a novas práticas de leitura e de escrita, até então inéditas. Chartier (1997, p. 93) nos chama também a atenção para o fato de que

esta revolução, fundada sobre uma ruptura da continuidade e sobre a necessidade de aprendizagens radicalmente novas, e portanto de um distanciamento com relação aos hábitos, tem muito poucos precedentes tão violentos na longa história da cultura escrita.

Estamos num ponto, como diz o entrevistador de Chartier neste texto, em que não há processo de aprendizagem transmissível de nossa geração à geração dos novos leitores. Ao contrário: aprendemos junto com eles e, muitas vezes, ensinados por eles.

Mais radical ainda é a ruptura se pensarmos na questão da multissemiose que as possibilidades multimidiáticas e hipermidiáticas do texto eletrônico traz para o ato de leitura: já não basta mais a leitura do texto verbal escrito - é preciso colocá-lo em relação com um conjunto de signos de outras modalidades de linguagem que o cercam, ou intercalam ou impregnam. Como lembram Moita-Lopes \& Rojo (2004, p. 38),

basta examinar a página de um jornal contemporâneo e compará-la com a de um jornal publicado há 20 anos para compreender a sofisticação do design gráfico atual, que atinge uma infinidade de mídias (hipertextos na Internet, textos na imprensa escrita, vídeos, filmes etc.). Que escolhas são feitas de cores, fotografias, desenhos etc. na construção do significado? Esse tipo de conhecimento tem sido apontado como extremamente importante para dar conta de letramentos multissemióticos que têm transformado o letramento tradicional (da letra) em um tipo de letramento insuficiente para dar conta dos letramentos necessários para agir na vida contemporânea. Além disso, tem sido enfatizado o modo híbrido ou multimodal como esses meios multissemióticos estão combinados e organizados em textos e hipertextos. Tais letramentos estão intimamente relacionados, portanto, com os requisitos do mundo do trabalho e da cidadania.

Vistas assim, muito rapidamente, algumas das características mais freqüentemente apontadas do texto eletrônico e algumas das decorrências dessas características para as práticas de leitura e para os letramentos digitais, vamos, neste texto, contrastar duas propostas de leitura em esfera didática ou escolar, de divulgação da ciência, em ambiente digital e em mídia impressa, sobretudo para avaliar o lugar que é designado ao leitor-aluno em cada uma delas e os tipos de atuação linguístico-discursiva que lhe são solicitados, de maneira a discutir as práticas de letramento que se dão nesses contextos.

\section{OSMATERIAISSOBANÁLISE: MATERIALDIDÁTICOIMPRESSOEELETRÔNICO}

Analisaremos aqui algumas atividades de duas propostas didáticas de tratamento de um mesmo tema do campo da divulgação científica, por dois materiais didáticos: uma 
ROJO - Letramentos digitais - a leitura como réplica ativa

seqüência didática ${ }^{5}(\mathrm{SD})$ impressa para a abordagem dos gêneros da divulgação científica ${ }^{6}$ junto a alunos de Ensino Médio e parte de um módulo de um curso à distância ${ }^{7}$ para professores de Ensino Médio.

A SD a ser analisada foi elaborada para utilização de professores da área de Ciências da Natureza, Matemática e suas Tecnologias, junto a seus alunos de Ensino Médio, visando a trabalhar as capacidades de leitura e escrita envolvidas no trato de textos em alguns gêneros da divulgação científica (verbetes, hipertextos, artigos de divulgação, textos didáticos, dentre outros). A SD, que conta com um livro do aluno e um do professor - que adiciona possíveis respostas para as atividades, sugestões de alternativas e informação suplementar ao professor -, organiza-se em uma apresentação e quatro partes, contendo, cada uma, uma série de atividades seqüenciais (de 3 a 6, quatro em média por parte), como se pode ver no Quadro 1:

\section{Quadro 1: Organização da SD}

\begin{tabular}{|l|l|}
\hline Apresentação & Proposta de produção de texto ao final \\
\hline \multirow{4}{*}{ Parte 1} & Como você vê a leitura desses textos? \\
\cline { 2 - 3 } Como você lê os textos de CNMT? & O que você sabe sobre esses gêneros de textos? \\
\cline { 2 - 3 } Parte 2 & Como você lê os textos de divulgação científica? \\
\hline \multirow{3}{*}{$\begin{array}{l}\text { Pensando sobre as ciências e sua } \\
\text { divulgação }\end{array}$} & Mito ou ciência? \\
\cline { 2 - 3 } & Conhecimento científico e senso comum \\
\cline { 2 - 3 } & Analisando o desenvolvimento das ciências \\
\cline { 2 - 3 } & Trabalhando com verbetes \\
\cline { 2 - 3 } & Criando verbetes e hipertextos \\
\hline
\end{tabular}

${ }^{5}$ Seqüências didáticas (SD) são um conjunto de atividades escolares organizadas, de maneira sistemática, em torno de um gênero textual oral ou escrito (DOLZ, NOVERRAZ \& SCHNEUWLY, 2004, p. 97).

${ }^{6}$ Rojo \& Lastoria (2007) Gêneros de divulgação científica - Seqüência didática. SP: SEE-SP/CENP, circulação restrita às escolas de Ensino Médio da Rede Pública Estadual de SP.

${ }^{7}$ Práticas de leitura e escrita. SP: SEE-SP/CENP/Rede do Saber/PUC-SP. Curso à distância elaborado por equipe ligada ao Programa de Pós-Graduação em Lingüística Aplicada da PUC-SP. 
Trab.Ling.Aplic., Campinas, 46(1) - Jan./Jun. 2007

\begin{tabular}{|c|c|}
\hline \multirow{2}{*}{ Parte 3} & Onde encontrar textos sobre temas científicos? \\
\hline & A organização dos textos na página \\
\hline \multirow{2}{*}{$\begin{array}{l}\text { Texto e imagem em material didático e } \\
\text { de divulgação científica }\end{array}$} & Leitura das ilustrações \\
\hline & Como relacionar imagens e textos? \\
\hline \multirow{2}{*}{ Parte 4} & Em contato com os temas dos textos \\
\hline & $\begin{array}{l}\text { Como se organizam os artigos de divulgação - as partes } \\
\text { do texto }\end{array}$ \\
\hline \multirow{2}{*}{$\begin{array}{l}\text { Textos didáticos e de divulgação } \\
\text { científica: os caminhos da leitura }\end{array}$} & Aspartes do texto e a progressão na leitura \\
\hline & O papel dos boxes \\
\hline
\end{tabular}

Segundo Dols, Noverraz \& Schneuwly (2004, p. 98), a estrutura de base de uma seqüência didática pode ser representada pelo seguinte esquema:

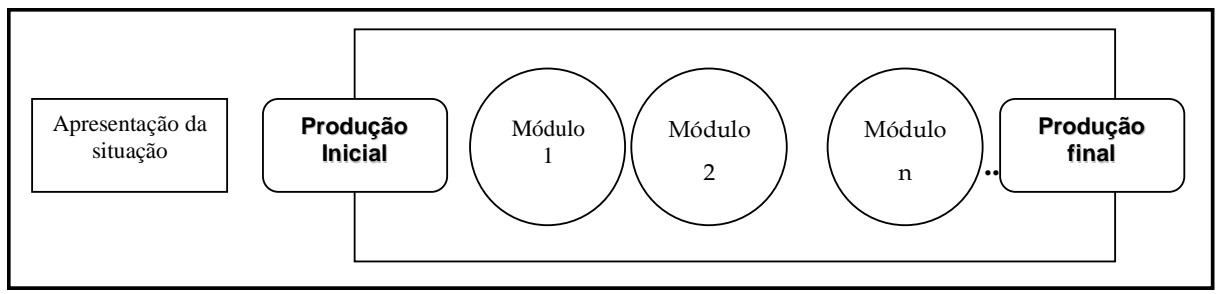

Figura 1: Esquema da seqüência didática

Assim, na apresentação da SD, as autoras detalham a situação de ensino em geral e buscam situar as produções dos alunos ao longo do processo, propondo a criação de um blog de divulgação científica dos grupos, ou, na impossibilidade de acesso a computadores conectados, de um mural da ciência.

Em seguida, na primeira parte da SD, ao invés de uma produção de texto num dos gêneros abordados, cuja finalidade normalmente é a avaliação diagnóstica, é proposta uma (auto-)avaliação das capacidades de leitura já desenvolvidas pelos alunos no que se refere ao trato com textos dos gêneros enfocados, o que indica a prioridade dada à leitura por esta SD. Os módulos de ensino que se seguem - Partes 2, 3 e 4 - tratam, respectivamente, da esfera de circulação desses textos - as ciências e sua divulgação -, de sua diagramação (mise-en-page) multimodal e de sua organização e textualidade, sempre da ótica das capacidades de leitura requeridas por essas propriedades. As produções de textos intermediárias e final - no blog ou no mural da ciência - também servem de base à avaliação de aprendizagem dos alunos sobre aspectos dos gêneros. 
Desta SD, tomaremos aqui para análise duas atividades do início da Parte 2, que tratam do funcionamento das esferas de produção e circulação dos textos: Mito ou ciência? (Atividade 1) e Conhecimento científico e senso comum (Atividade 2) por tratarem dos mesmos temas abordado no início do Módulo 2 do curso on line.

O curso on line Práticas de leitura e escrita é uma proposta de formação continuada a distância (via WEB) para professores de Ensino Médio. Baseada nas reflexões do Círculo de Bakhtin sobre linguagem e enunciação - em especial, na Teoria dos Gêneros do Discurso (Bakhtin/Volochinov, 1929; Bakhtin, 1952-53/1979; 1934-35/1975) -, a proposta visa uma reflexão por parte dos docentes de Ensino Médio - de todas as áreas e disciplinas ${ }^{9}$ - sobre as práticas de letramento, de leitura e de escrita que se exercem, tanto na escola como fora dela, na tentativa de compatibilizar as exigências sociais da contemporaneidade quanto aos tipos e níveis de letramento e as práticas escolares.

A idéia é refletir sobre e exercer com os professores-alunos essas práticas de leitura e escrita, em ambientes digitais interativos, e, após essas vivências, retirar decorrências e estratégias de abordagem da circulação, compreensão e produção de textos - em diferentes gêneros, modalidades e linguagens - nas salas de aula de Ensino Médio.

O Programa utiliza as ferramentas WEB disponíveis na Rede do Saber, de forma a potencializar a capacidade instalada, mas customizadas para que sejam atingidos os objetivos propostos. As ferramentas incluem:

$\sqrt{ }$ Ferramentas de informação (em hipertexto e hipermídia): Estes recursos permitem a publicação dos conteúdos do curso: textos e hipertextos, hipermídia, glossários, materiais de apoio e de referência, etc. Incluem áreas como quadro de avisos, agendas, biblioteca etc.

$\sqrt{ }$ Ferramenta de organização das propostas de trabalho: Este recurso permite a publicação das atividades relacionadas ao conteúdo que está sendo abordado no curso. É o espaço destinado à apresentação das propostas de trabalho, estruturadas de tal forma que permitam o acompanhamento e organização do trabalho dos alunos.

$\sqrt{ }$ Ferramenta de comunicação assíncrona (Fórum de Discussão): Esse recurso permite a criação de linhas de discussão assíncrona. As mensagens/respostas enviadas podem ser organizadas de diferentes maneiras, facilitando o acompanhamento dos

${ }^{8} \mathrm{O}$ curso foi elaborado para a Secretaria de Estado da Educação de São Paulo - SEE-SP sob a responsabilidade da PUC/SP, por meio do Programa de Pós Graduação em Lingüística Aplicada e Estudos da Linguagem (LAEL), atendendo às exigências do termo de referência do Edital PROMED para contratação. A execução do Programa contou com a colaboração da Rede do Saber, rede gestora de formação continuada de gestores educacionais da SEE-SP. O curso cumpre uma das etapas do PROMED (Programa de Melhoria e Expansão do Ensino Médio) em São Paulo, cujas ações vêm sendo implementadas desde dezembro de 2000, a partir do convênio firmado com o Distrito Federal e também com o PNUD - Programa das Nações Unidas para o Desenvolvimento (Projeto BRA 99 / 012).

${ }^{9} \mathrm{Na}$ qualidade de participantes como professores-alunos, professores interessados de todas as áreas e disciplinas do Ensino Médio de mais de 3000 escolas. Embora o edital estabeleça apenas professores como público alvo, o Programa abrangeu os Assistentes Técnico-Pedagógicos (ATPs) e Professores Coordenadores (PCs) na qualidade de professores-mediadores. Tal iniciativa contribui para a formação de gestores pedagógicos da rede, o que também se reverte para a própria formação dos professores. 
comentários sobre um tema e as buscas de mensagens. O professor pode criar, renomear, configurar ou excluir um determinado Fórum.

$\sqrt{ }$ Ferramenta de avaliação: Permite acompanhar os processos avaliados sistematicamente.

$\sqrt{ }$ Ferramentas de registros de participação: Registram os acessos às ferramentas $\mathrm{e}$ permitem um acompanhamento da freqüência e participação de todos nos diferentes espaços dos ambientes de aprendizagem.

Além disso, incorporam-se também ao curso as ferramentas usuais de navegação na WEB, disponíveis na própria rede, e de tratamento e edição de textos e cálculos, disponibilizadas por diferentes softwares ${ }^{10}$.

O curso, previsto para 40 semanas (180h) tem uma estrutura modular bastante semelhante à da $\mathrm{SD}$, com a diferença que são seus objetos de ensino:

- Navegação e uso de ferramentas WEB:

${ }^{\circ}$ Próprias do ambiente do curso (Prometeus e Learning Space) - Módulo 1

${ }^{\circ}$ De uso geral na WEB e no manejo digital de textos, sons e imagens (ferramentas e alguns softwares) - todos os Módulos;

- Gêneros de diferentes esferas de circulação (sobretudo, em mídias digital e impressa);

- Capacidades de leitura e escrita exigidas por estes gêneros, mídias e situações; e

- Elaboração de projetos didáticos.

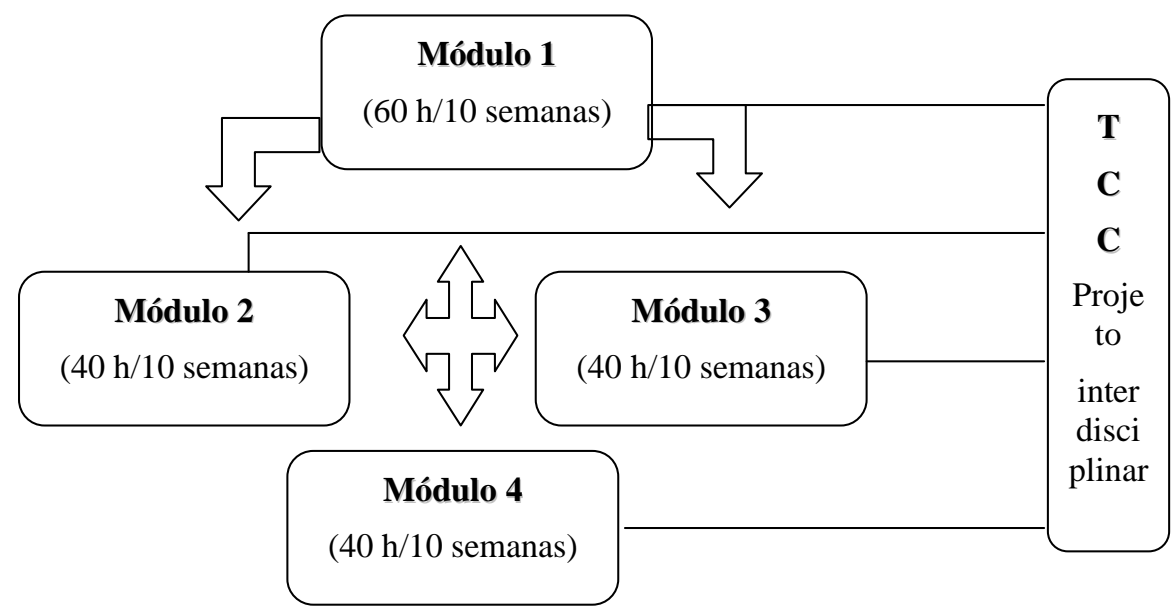

Figura 2: Estrutura modular do curso on line

${ }^{10}$ Para maiores detalhes a respeito, ver Rojo, Barbosa \& Collins (2006). 
ROJO - Letramentos digitais - a leitura como réplica ativa

Os gêneros abordados são de diversas esferas, com privilégio para as ferramentas computacionais e as esferas cotidianas e burocráticas no Módulo 1; para a esfera escolar e da divulgação científica, no Módulo 2; do jornalismo de informação e de opinião, no terceiro, e das artes (literárias, musicais, plásticas), no último. Neste texto, analisaremos algumas atividades iniciais do Módulo 2 - Em dia com a ciência e o conhecimento: a escola no século XXI.

A organização do Módulo 2 também é a de Abertura e mais quatro Unidades (a terceira delas, eletiva), com atividades seqüenciais. A Figura 3 mostra a organização do Módulo:

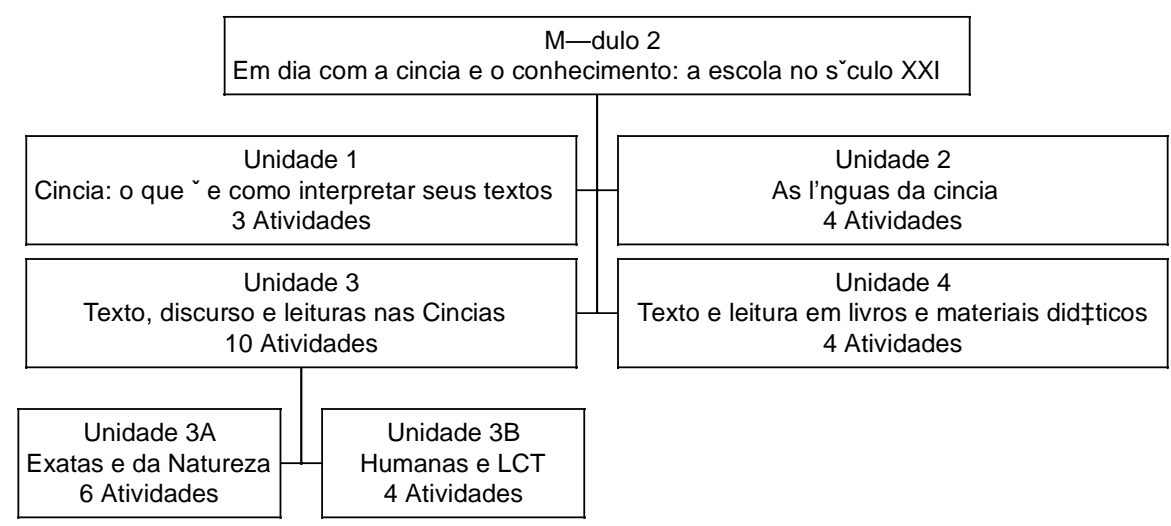

Figura 3: Estrutura organizacional do Módulo 2 do curso

\section{MATERIALDIDÁTICOIMPRESSOEDIGITAL:CONTRASTANDOPOSSIBILIDADES DELEITURA}

Como vimos na primeira parte deste texto, interessa-nos nesta análise discutir o lugar que é designado ao leitor-aluno em cada uma das propostas didáticas e os tipos de atuação lingüísticodiscursiva que lhe são possibilitados, de maneira a discutir as práticas de letramento que se dão nesses dois contextos.

Para analisar o lugar que o leitor-aluno ocupa na apreciação de valor que sobre ele faz a autoria dos materiais, vamos analisar dois pontos de vista em especial: o grau de interatividade (recurso a dispositivos interativos ou propostas de interação) de cada uma das propostas e o tipo de capacidade de leitura exigida pelos exercícios: se de extração da informação textual ou de réplica(s) ao texto(s) em circulação. Para analisar os tipos de atuação lingüístico-discursiva, vamos observar, especialmente, as relações entre leitura e escrita, autor e leitor implicadas nas propostas e as características de multimodalidade ${ }^{11}$ dos textos e sua exploração.

\footnotetext{
${ }^{11}$ Multimodalidade aqui está sendo entendida num sentido amplo, como a presença, num mesmo texto ou enunciado, de maneira integrada e relacional, mutuamente constitutiva, de diferentes modalidades de linguagem (verbal oral, verbal escrita, imagem, imagem em movimento etc.).
} 
O tema geral das atividades a serem analisadas, em um e em outro material didático, é o das relações entre ciência, mito e senso comum.

\section{Curso on line}

Módulo 2 - Em dia com a ciência e o conhecimento: a escola no século XXI Unidade 1 - Ciência: o que é e como interpretar seus textos

Atividade 1

O que é ciência para nós?

Vocês vão realizar esta atividade em grupos de pessoas que trabalham na mesma área disciplinar (Ciências da Natureza e Matemática ou Ciências Humanas e Linguagens, Códigos e Tecnologia). Os grupos foram organizados pelo seu professor e estão publicados no Fórum, tema Mural da Ciência.

$\cdots$

Vá até o Fórum, entre no tema Mural da Ciência e verifique qual é o seu grupo.

A seguir, entre no tema Mural da Ciência - Grupo X e troque mensagens com seus parceiros para se conhecerem melhor e negociarem um representante para o grupo. Como vocês sabem, o representante tem uma função específica na organização das atividades coletivas.

E então, seu novo grupo já está formado? Já sabe quem são seus colegas? Já escolheram um representante para o grupo? Agora, vamos iniciar a atividade propriamente dita.

Volte ao Fórum no tema do seu grupo e juntos, elaborem um parágrafo que defina, do ponto de vista do grupo, o que é a ciência para a sua área ou disciplina.

Lembre-se de que a tarefa é produzir um parágrafo coletivamente, de modo a expressar a opinião do grupo. Por isso, negociem as diferentes concepções que eventualmente tenham até o grupo chegar a um consenso.

Quando o trabalho em grupo estiver concluído, o representante deve publicar o resultado no tema Mural da Ciência. Lembre-se, basta selecionar, copiar e colar.

Após publicarem o trabalho do grupo, aproveitem para ler os textos dos outros colegas e confrontá-los, buscando pontos em comum ou divergentes.

Ao concluírem a atividade anterior, você e seu grupo devem ter aprimorado e formalizado uma concepção de ciência. A seguir, retornem ao Fórum, no tema específico do seu grupo, para dar continuidade à atividade. 
ROJO - Letramentos digitais - a leitura como réplica ativa

Tomando por base o parágrafo que redigiram juntos e os textos publicados no Mural da Ciência, construam agora um elenco de aspectos que caracterizam a ciência.

Quando a lista estiver concluída, o representante do grupo deve publicá-la no tema Mural da Ciência.

Depois de publicada a lista de características elaborada por seu grupo, leia as listas produzidas pelos outros grupos.

...

E então? Já leu as definições de ciência e as listas de características dos outros grupos? Achou semelhanças e diferenças entre a proposta de seu grupo e as outras propostas?

Para finalizarmos esta atividade, você e seu grupo devem reavaliar a definição de ciência que fizeram inicialmente. Registrem as principais diferenças entre a primeira versão do grupo e a versão final da turma. Para essa reelaboração, usem novamente o Fórum, no tema específico do seu grupo.

$\begin{array}{ll}\text { Quero Continuar } & \text { TUTORIAIS } \\ \text { mais tarde } & \text { Copiar e Colar } \\ \text { Atividade Concluida } & \text { Debates no Fórum }\end{array}$

Somente depois desta Atividade 1 - encarada como ativação de conhecimento prévio sobre o tema - é que a Atividade 2 (Lendo sobre o que é ciência) propõe a leitura de um texto de Carl Sagan ${ }^{12}$, sobre o qual se exercem várias capacidades de leitura, em geral centradas na apreensão do conteúdo do texto: antecipação e checagem dos temas do texto; localização e cópia de informação relevante; generalização, seleção por relevância e síntese (resumo) e inferências globais e locais. Segue-se a Atividade 3 ( $O$ que é ciência para os outros?), em que o aluno-leitor poderá acessar links para dois outros textos intitulados $O$ que é ciência ${ }^{13}$ Esta última Atividade solicita do aluno-leitor que:

Identifique as características atribuídas à ciência nos textos lidos. Se quiser, acrescente também as propriedades da ciência mencionadas por Carl Sagan. Depois, elabore um esquema com as características que você levantou nos textos. Envie seu esquema anexado em uma mensagem ao Fórum de seu grupo. Atenção: Esta atividade também está agendada.

\footnotetext{
${ }^{12}$ Podemos conhecer o universo? Reflexões sobre um grão de sal. In: SAGAN, C. (1974) O Romance da Ciência. RJ: Francisco Alves, 1982, p. 27-32.

${ }^{13} \mathrm{Um}$, de Paul Davis, acessível em http://www.cfh.ufsc.br/ wfil/davies.htm, e outro acessado na página http://www.ciencia.pro.br/users/erasmo/oque.htm, do site Ciência.pro.br, que, ele próprio, incorpora citações de vários outros textos e oferece links para duas outras páginas: What is science? (.se) e $\underline{\text { A ciência }}$ da ciência (.br).
} 
Reúna-se com seu grupo interdisciplinar em Fórum. Levando em consideração a lista de características criada na Atividade 1, que está disponibilizada no Mural da Ciência, quais são os pontos comuns e quais os divergentes com os esquemas feitos na atividade anterior? Proponha as mudanças que vocês acham necessárias na lista consensual da Atividade 1, procurando justificar suas novas propostas. Coloquem a proposta do seu grupo revista no Mural da Ciência. Pensem um esquema visualmente bem interessante para apresentá-la.

...

Com base nas capacidades de leitura que exploramos nesta Unidade, construa, individualmente, um roteiro de leitura que poderia guiar, em sua sala de aula, a exploração de leitura inicial do texto de Paul Davies sobre O que é ciência? Se quiser, amplie para além do que já exploramos as possibilidades de questões, por exemplo, colocando em discussão a opinião de Davies sobre a acupuntura chinesa. Ao terminar o roteiro, publique-o em seu Portfolio, para depois reaproveitá-lo, como tal ou aplicado a outros textos se necessário, na Unidade de Ensino que está elaborando.

O que salta aos olhos no conjunto das atividades deste início de Módulo é o alto grau de interatividade, de produção de textos escritos e de intertextualidade das propostas didáticas: na primeira atividade, o aluno-leitor tem pelo menos quatro oportunidades de interação escrita variada com seus colegas para trocar e afinar opiniões e deve redigir e depois revisar um texto coletivo. Ou seja, a proposta dá lugar primeiro à voz do aluno, partindo do debate no grupo, por meio de Fóruns. Em seguida, nas outras atividades, vai confrontar este conjunto de posições assumidas e de textos escritos, com as de cientistas e divulgadores da ciência. Como diria Chartier (1997), não é uma proposta de subordinação à autoridade dos textos e dos autores, mas de apropriação (tornar próprio, fazer seu) das palavras dos autores, no berço das palavras-próprias que as antecederam.

Por fim, o aluno-professor vai pensar na transposição das atividades que vivenciou para os seus alunos, visando desenvolver suas capacidades leitoras. Nesta Unidade 1, não há trabalho com a forma composicional ou com a multimodalidade dos textos lidos - que, aliás, não é forte - e este foco somente vai aparecer nas Unidades eletivas 3, em textos de áreas específicas do conhecimento, como é o caso de gráficos e tabelas em textos de ciências exatas e fotos em trabalhos de antropologia etnográfica.

No caso da exploração do mesmo tema proposta na SD, abre-se o módulo ou unidade com um discurso autoral sobre o que é ciência, de meia página, ilustrado com quatro fotos que estabelecem um diálogo intertextual com o texto propriamente dito.

\section{Parte 2 Pensando sobre as ciências e sua divulgação}

O que é ciência? O que são ciências da natureza? Nunca houve uma forma única de entender esse termo. Ainda hoje, continuam divididas as opiniões acerca do que deve ou não ser considerado "científico", sendo difícil estabelecer uma definição rigorosa e consensual para "ciência". Numa primeira resposta pode-se dizer que a 
ROJO - Letramentos digitais - a leitura como réplica ativa

ciência é fruto de uma indagação, de uma busca de respostas para questões relativas aos fatos da natureza, incluindo o que acontece com o ser humano, numa tentativa de entender como ocorrem e por que são como são. Muitas das perguntas mais elementares que a humanidade se colocou desde os tempos remotos podem dar origem a estudos científicos. Eis alguns exemplos: por que chove? O que é o trovão? De onde vem o relâmpago? Por que as ervas crescem? Por que existem os montes? Por que razão tenho fome? Por que meus semelhantes morrem? Por que cai a noite e a seguir vem o dia de novo? O que são as estrelas? Por que razão os pássaros voam? Por que os objetos caem no chão? [Ilustração: série de quatro fotos/ilustrações - duas de galáxias, uma de telescópio e uma de dinossauro]

Segue-se a Atividade 1:

\section{Atividade 1 - Mito ou ciência?}

1 Leia este texto.

A origem dos diamantes

(Texto extraído do livro Lendas e mitos do Brasil, de Theobaldo Miranda Santos. São Paulo: Nacional, 2004)

2 A lenda atribui a origem dos diamantes a que fato? Segundo a lenda, como foram formados? Anote em seu caderno.

3 Leia esta outra lenda.

A lenda da chuva

(Conforme relato verbal do índio Puhuy Maxacali, ouvido e transcrito por Luiz Carlos Lemos, retirado de <http://jangadabrasil.com.br/ colaboracoes/13.htm> Acesso em 14/07/2006)

4 A que a lenda atribui a origem da chuva? Segundo a lenda, como surgiram os animais? Anote em seu caderno.

5 Agora, é sua vez: qual a explicação científica da chuva? Anote também.

6 Conclua então: que diferença você vê entre o pensamento mítico e o científico? Anote.

Em seguida, reaparece o discurso autoral ilustrado por fotos ou reproduções de telas, de certa maneira retocando e corrigindo a resposta que o aluno-leitor possa ter dado à questão 6. Este proceder é, como veremos, recorrente nas atividades:

As respostas míticas ou religiosas aos problemas da natureza apelam para razões que não dependem da observação ou da racionalidade humana: são associadas à vontade de um Deus ou de deuses, espíritos e outros seres animados, e suas explicações assumem a forma de narrativas (mitos ou lendas) que contam uma história sobre a origem dos fenômenos. Essas respostas nem sempre se baseiam em estudos sistemáticos da natureza; estão associadas a crenças e não encorajam a crítica, pois são a aceitação mítica, que submete os homens a um poder mais alto. Por outro lado, as 
explicações míticas e religiosas de um dado povo constituem, muitas vezes, códigos de conduta social, moral e ética que, integrados com a origem mítica do Universo, determinam o que se deve e o que não se deve fazer. [ilustração - reprodução de tela e foto de satélite meteorológico em órbita]

7 Com a lenda da chuva, o que se pretende ensinar?

8 O desenvolvimento da ciência na história da humanidade vem se pautando pelo mesmo tipo de princípio? Justifique.

As explicações míticas e religiosas são, de certa forma, antepassados das ciências, pois, apesar de submeterem a natureza e os seres humanos a poderes superiores, já buscavam respostas para alguns fenômenos naturais e sociais, constituindo um dos primeiros passos em direção às ciências.

\section{Atividade 2 - Conhecimento científico e senso comum}

Leia os dois textos a seguir.

Texto 1

Características do senso comum

Texto 2

Características do conhecimento científico

1 Com base nesses dois textos, complete a frase em seu caderno: A ciência se distingue do senso comum porque...

2 Apresente, ou recolha entre conhecidos, diferentes explicações para a queda abrupta de uma pedra ou a quase flutuação de uma pena. Registre as explicações, indicando se cada uma delas tem características científicas (usando uma lei universal) ou de senso comum (justificativas casuísticas).

3 Dê exemplos de explicações de senso comum que são refutadas por explicações científicas.

4 Para um fenômeno como a origem da vida humana, procure identificar explicações consideradas científicas, míticas ou religiosas.

Atividade 3 - Analisando o desenvolvimento das ciências

As ciências da natureza conheceram desenvolvimento sem precedente nos séculos XIX e XX. Uma "enxurrada" de inventos, ao longo desse período, tornou nossa vida mais duradoura e suportável, quando não mais prazerosa. [...]

1 Observe as imagens e responda em seu caderno: você acha que os resultados científicos e as tecnologias significam um progresso para a humanidade, mais qualidade de vida e maiores possibilidades de lazer e prazer? Dê sua resposta e justifique sua opinião em seu caderno. [Série de 10 fotos reproduzindo a bomba de Hiroshima, um usuário frente a um computador, o acidente nuclear de Chernobil (2), antena parabólica, armas de guerra de alta tecnologia, cartaz de cinema, irrigação mecanizada do campo, erosão e seca, aparelho de tomografia computadorizada]

Aqui, ocorre uma condução discursiva que parece ser exatamente o inverso da anteriormente analisada - a voz do aluno é a última a se manifestar, em geral em anotações que não serão necessariamente retomadas, sendo privilegiada a voz dos textos e, 
principalmente, a da autoria do material didático - que introduz os temas e focos, busca guiar o olhar do leitor, traz questões que vão direcionar a leitura, corrige ou dá imediatamente respostas que o aluno-leitor acabou de buscar. Na Atividade 1, as questões propostas ao alunos são quase todas de localização e anotação de informação textual. Apenas na questão 5 se lhe solicita uma informação que não está no texto (marcada por um introdutor Agora é a sua vez:). Mas a voz solicitada é a da ciência e não a sua: ele deve revozear conhecimentos prévios, para depois comparar com as anotações copiadas dos textos (questão 6), retirando uma conclusão que a autoria se apressa em fornecer também, no parágrafo seguinte. As questões 7 e 8 são mais inferenciais e mais abertas, mas sempre subordinadas à condução autoral da compreensão dos textos. De maneira cada vez mais inferencial e baseada no conhecimento de mundo do aluno (descendente), as Atividades 2 e 3 repetem o procedimento: o aluno-leitor deve buscar em seu conhecimento armazenado sobretudo exemplos para a posição dos textos e da autoria.

Vale observar também que a composição de página com recursos multimodais é muito mais utilizada no material impresso - sempre ilustrado - que nas páginas do curso on line - essencialmente verbais escritas. Mas sempre com este valor de ilustração, que embora possa ser objeto de relação intertextual, vem somente reforçar o efeito de sentido buscado no texto verbal.

A Atividade 3 inclusive exige que o aluno-leitor lide com leitura de imagens para responder à questão. Mas essas imagens ali estão para induzir o tema (no sentido bakhtiniano) da resposta que a autoria espera - considerando benefícios e malefícios do progresso científico. Portanto, trata-se de uma falsa construção de opinião por parte do aluno-leitor. E as capacidades de leitura multimodal não são efetivamente convocadas para a leitura.

Que lugar é reservado ao aluno-leitor nessas propostas? No primeiro caso, sua compreensão do mundo e dos temas forma um esteio de palavras-próprias e alheias (dos colegas de grupo) sobre o qual as contribuições dos textos de autoridade vem se assentar. $\mathrm{O}$ aluno-leitor é visto e convocado como um produtor de discurso/texto. Na segunda proposta, o aluno-leitor é visto como um revozeador da autoridade (do texto de autor, dos textos intercalados). Ele é visto como um leitor reverente, disciplinado, obediente, como diria Chartier: um leitor da era do livro.

O que ocorre no ambiente digital que o impresso apaga? Porque um se apresenta tão mais interativo e internamente persuasivo que o outro, mais centrado na autoridade do texto?

O leitor pode objetar que se trata simplesmente de uma questão de estilo didático da autoria. Sim, é fato. O suporte ou mídia por si só não acarretam um estilo mais de autoridade ou de apropriação. Há outros elementos a serem considerados aqui: no primeiro caso, os autores estão se dirigindo a professores-alunos e, no segundo, a alunos de Ensino Médio. Possivelmente, a valoração da autoria a respeito destes interlocutores, do que podem ou deixam de poder, do que são capazes de fazer, é bastante diversa.

Mas não há também como negar que, na história do livro e da leitura, o impresso favorece o espaço discursivo autoral - é claro que o autor poderá escolher como vai usá- 
lo, se a favor de sua autoridade ou da apropriação do leitor e essa é uma questão de estilo. Mas seu espaço discursivo e sua identidade enquanto autor estão garantidos. Chartier (1997: 32) lembra-nos de que

\begin{abstract}
é Foucault quem sugere que, numa determinada sociedade, certos gêneros para circular e serem recebidos, têm necessidade de uma identificação fundamental dada pelo nome de seu autor, enquanto outros não. Se considerarmos um texto de direito ou uma publicidade no mundo contemporâneo, alguém os escreveu, mas eles não têm autores; nenhum nome próprio lhes é associado.
\end{abstract}

Nesta linha de pensamento, as páginas de ambiente virtual fazem parte desses gêneros que prescindem da autoria para existir; os livros e impressos didáticos, não. Note o leitor que é mesmo difícil atribuir com clareza a autoria do curso on line, a não ser a um coletivo, ao contrário da SD. Assim é que podemos pensar que o texto eletrônico e a esfera digital favorecem um apagamento do discurso autoral em materiais didáticos, que pode tender a se restringir a um conjunto de instruções que, para compensar, pode contar com a linkagem a um banco de textos quase infinito, sem limite de páginas, cadernos ou cansaço do leitor, que pode ou não clicar o link, quase que a seu bel prazer (um pouco restringido por efeitos escolares, é verdade, no caso dos materiais didáticos).

A segunda e paradoxal característica bastante saliente é a maior interatividade do material digital. Contando com ferramentas de comunicação síncrona e assíncrona, o curso on line não se passa de fazer uso delas; ao contrário. Já o impresso que circulará na sala de aula prefere colocar o aluno em interação com o texto escrito e não com seus colegas e sobretudo não com o professor. A voz do autor do material tende quase sempre a substituir ou ignorar a voz do professor, dirigindo-se diretamente ao aluno e encarregando-se da aula. Entre outros aspectos aqui, devemos levar em conta que este tipo de material didático é herdeiro dos apostilados e dos estudos dirigidos.

Um último comentário pode nos aproximar um pouco mais do tema deste número da revista: os letramentos críticos. Todas estas considerações à parte, é óbvia a constatação de que uma leitura reverente à autoridade do texto e do autor (autoritária, em termos da tradução que se fez de Bakhtin), a leitura de revozeamento não favorece os letramentos críticos. Ao contrário, uma leitura de réplica ativa, que contrapõe ao enunciado alheio a própria voz, que dialoga com o outro é fundamental para a sua construção. Já Bakhtin (1970: 366) dizia que uma compreensão ativa "não renuncia a si mesma, ao seu próprio lugar no tempo, à sua cultura, e nada esquece. O importante no ato de compreensão é a exotopia do compreendente no tempo, no espaço, na cultura, a respeito do que ele quer compreender."

Nessa perspectiva, a respeito da formação de nossos leitores em termos de letramentos críticos, Farahmandpur \& McLaren (2001: n.p.) vem nos lembrar de que

um grande desafio em formar alunos para o letramento crítico não está somente em proporcionarlhes experiências de aprendizado significativas (i.e., através de práticas de numeramento, de letramento digital, de letramento cultural e do desenvolvimento de capacidades de letramento crítico), mas em validar e legitimar as experiências que os alunos trazem de suas vidas 
cotidianas para a sala de aula. As experiências dos estudantes podem estar relacionadas a um currículo baseado em temas, desenhado para facilitar o letramento econômico, midiático, o eco-letramento, o letramento para o consumo e outros, relacionados às políticas sociais e educacionais postas em movimento pelo desregrado capitalismo global (tradução minha).

\section{$\overline{\text { REFERÊNCIASBIBLIOGRÁFICAS }}$}

BAKHTIN, M. M./VOLOCHÍNOV, V. N. (1989). Marxismo e Filosofia da Linguagem. São Paulo: Hucitec. (publicação original em 1929).

BAKHTIN, M. M. (1988). O discurso no romance. In Questões de literatura e de estética. São Paulo: EduneSP/ Hucitec, p. 71-210. (texto original de 1934-1935, publicação em 1975).

. (2003). Os gêneros do discurso. In Estética da criação verbal, p. 261-306. (texto original de 19521953, publicado em edição póstuma em 1979).

(2003). Os estudos literários hoje (Resposta a uma pergunta da Revista Novi Mir). In Estética da criação verbal, p. 359-366. (texto original de 1970, publicado pela Revista Novi Mir, $n^{\circ}$ 11, pp. 237-240).

BEAUDOUIN, V. (2002/6). De la publication à la conversation. Lecture et écriture électroniques. Réseaux, $\mathrm{n}^{\circ} 119$, pp. 199-225. <http://www.cairn.info/1>, acessado em 26/03/2007.

CHARTIER, R. (1998). A aventura do livro: Do leitor ao navegador. SP: EDUNESP. (texto original publicado por Les Editions Textuel em 1997).

DOLZ, J.; NOVERRAZ, M. \& B. SCHNEUWLY. (2004). Sequiências didáticas para o oral e a escrita: apresentação de um procedimento. In Schneuwly, B.; Dolz, J. et al. Gêneros orais e escritos na escola. Campinas: Mercado de Letras. pp. 95-128. Tradução e organização de Rojo, R. H. R. \& Cordeiro, G. S. (texto original de 2001).

FARAHMANDPUR, R. \& P. MCLAREN. (2001). Critical Literacy for Global Citizenship. Center X - Fórum, Vol 1, $n^{\circ}$ 2, UCLA Graduate School of Education \& Information Studies. <http://www.centerx.gseis.ucla.edu/ forum/spring01/ critical.htm>, acessado em 26/03/2007.

LAHIRE, B. (1993). Culture écrite et inégalités scolaires - Sociologie de l' "échec scolaire' à l'école primaire. Lyon: PUL.

LEMKE, J. L. (1998). Metamedia literacy: transforming meanings and media. In D. Reinking; L. Labbo; M. McKenna; R. Kiefer (Org.). Handbook of literacy and technology: transformations in a post-typographic world. Hillsdale, NJ: Erlbaum. pp. 283-301.

LÉVY, P. (1997). Cyberculture. Paris: Editions Odile Jacob. . (1998). Qu'est-ce que le virtuel? Paris: La Découverte.

MOITA-LOPES, L. P. \& R. H. R. ROJO. (2004). Linguagens, Códigos e suas Tecnologias. In Brasil/MEC/SEB/ DPEM. Orientações Curriculares de Ensino Médio. Brasília, DF: MEC/SEB/DPEM. pp. 14-56.

ROJO, R. H. R.; BARBOSA, J. P. \& H. COLLINS. (2006). Letramento digital: um trabalho a partir dos gêneros do discurso. In Karvoski, A. M.; B. Gaydeczka; K. S. Brito (Org.) Gêneros textuais - reflexões e ensino. RJ: Ed. Lucerna. p. 107-130.

ROJO, R. H. R. \& C. LASTORIA. (2007). Gêneros da divulgação científica - Sequiência didática. SP: SEE-SP/ CENP, circulação restrita. 